\title{
Pour une histoire sociale de la mode hongroise
}

For a Social History of Hungarian Fashion

Megjegyzések a magyar divat társadalomtörténetéhez

\section{Anna Keszeg}

\section{OpenEdition}

\section{Journals}

Édition électronique

URL : https://journals.openedition.org/efo/7403

DOI : $10.4000 /$ efo.7403

ISSN : 2275-1947

\section{Éditeur}

INALCO

Édition imprimée

ISBN : 978-2-343-12463-6

ISSN : 0071-2051

\section{Référence électronique}

Anna Keszeg, «Pour une histoire sociale de la mode hongroise », Études finno-ougriennes [En ligne], 48 2017, mis en ligne le 19 juillet 2017, consulté le 08 juillet 2021. URL : http://journals.openedition.org/ efo/7403 ; DOI : https://doi.org/10.4000/efo.7403

Ce document a été généré automatiquement le 8 juillet 2021.

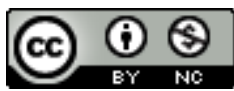

Études finno-ougriennes est mis à disposition selon les termes de la Licence Creative Commons Attribution - Pas d'Utilisation Commerciale 4.0 International. 


\title{
Pour une histoire sociale de la mode hongroise
}

\author{
For a Social History of Hungarian Fashion \\ Megjegyzések a magyar divat társadalomtörténetéhez
}

\section{Anna Keszeg}

1 Le rapport au vêtement, de même que la place occupée par l'habillement dans l'imaginaire social de telle ou telle culture semblent aller de soi. Pourtant, ces phénomènes sont difficiles à saisir, puisque même une définition universelle de la mode ne peut être qu'approximative. Dans les pages suivantes, nous allons essayer d'appréhender les problèmes auxquels se heurte un projet d'histoire sociale de la mode et $d u$ vêtement hongrois. Le principal enjeu de notre entreprise est d'indiquer les dimensions de cette problématique qui doivent être prises en compte pour éviter une chronologie qui se limite à l'identification des commencements tardifs, aux époques de crise et à des périodisations formelles. Il nous semble que les questions se posent au moins à trois niveaux : tout d'abord, au niveau d'une approche discursive relative à la place que les mots et les expressions liés à la mode occupent en Hongrie ; ensuite, nous devons prêter attention aux moments majeurs de l'histoire du phénomène vestimentaire et de l'apparition tardive de la mode dans l'histoire de l'habillement; enfin, il faut relever des difficultés plus pointues présentes sur le plan de l'analyse des faits et des processus de l'industrie de la mode et de sa professionnalisation dans la culture nationale hongroise.

2 Avant de commencer notre investigation, faisons un petit détour par la littérature académique concernant l'étude scientifique de la mode. En 1987, dans son livre devenu incontournable et intitulé l'Empire de l'éphémère. La mode et son destin dans les sociétés modernes, Gilles Lipovetsky remarque amèrement que la mode n'est toujours pas un sujet de recherche académiquement reconnu (1987, p. 11). Durant les trois décennies qui se sont écoulées depuis la parution de ce livre, nous avons assisté à une vraie autonomisation du champ de recherche de la théorie de la mode et à la naissance des fashion studies (sciences de la mode). Une importante production de littérature scientifique a lieu régulièrement et les chercheurs sont plus rarement obligés 
d'apporter des arguments pour soutenir le caractère sérieux de leur sujet de recherche. La Berg Fashion Library, éditeur de la monumentale Berg Encyclopedia of World Dress and Fashion ${ }^{1}$, tout comme sa revue académique, Fashion Theory, ne laissent aucun doute sur la scientificité des recherches concernant la mode. Cependant, la remarque de Gilles Lipovetsky continue à être valable pour le champ académique hongrois. En France, en Belgique, en Angleterre et aux États-Unis, le discours scientifique sur la mode s'est accompagné d'une sérieuse patrimonialisation de la mode. En Hongrie, les traités ayant une ambition scientifique se limitent pour la plupart à des analyses historiques positivistes, à un ouvrage dédié à la sociologie de la mode (Zsolt, 2007), ainsi qu'à deux volumes d'Antal Csipes (2011) qui se trouvent à la charnière d'un discours scientifique et d'un discours à la portée plus générale. Citons le plus récent de ses travaux, intitulé Une approche sérieuse de la mode :

$\mathrm{Au}$ troisième millénaire, la mode est devenue un phénomène culturel de première importance. La société s'est restructurée à cause de la consommation en masse et des médias : la mode ne se ramène plus aux vêtements, elle influence de plus en plus de domaines. Le design, la publicité, le sport, la santé, les coutumes et l'apparence ont de l'emprise sur toute la société et contribuent à sa restructuration. (Csipes, 2011, p. 7) ${ }^{2}$

Malgré cette introduction prometteuse, le livre se contente de faire un état des lieux sans l'accompagner d'analyses plus systématiques et centrées sur des exemples concrets. Loin de nier l'importance de ces ouvrages, nous attirons l'attention sur la nécessité de dépasser ce stade de l'enthousiasme devant la nouveauté du champ de recherche. L'approche généraliste reste aussi le trait majeur du livre de Katalin F. Dózsa (2014), qui réunit des études historiques, propose une chronologie globale de la mode ainsi qu'une cartographie des analyses académiques sur la mode. Cet ouvrage a tout d'un manuel universitaire.

4 Nous pouvons assister également à l'émergence d'une nouvelle génération de chercheurs (pour la plupart, des historiens) qui se consacrent à des recherches plus spécifiques. Mais la tendance à l'anglicisation qui se manifeste dans tous les domaines scientifiques, et en particulier dans ces domaines récents, augmente le risque que l'autonomisation du champ de recherche ne se produise pas et que les chercheurs attirés par le sujet s'attachent directement aux discours scientifiques globaux.

\section{Histoires de mots : mode et « divat »}

5 Après ce bref état des lieux, tournons-nous vers le premier aspect de notre investigation pour analyser le sens des mots désignant le phénomène contemporain du comportement vestimentaire. Un parcours des ouvrages de référence sur la mode démontre qu'il y a trois dimensions importantes exposées dans les définitions: (1) les approches qui considèrent la mode dans son rapport à la temporalité, au changement, à la vitesse et à l'éphémère - cette façon particulière de s'habiller est spécifiquement occidentale et moderniste ; (2) la mode désigne un rapport spécifique à la société, aux autres, une manière d'imiter les autres et se faire imiter par les autres - c'est ce que Gilles Lipovetsky définit comme "schéma de la distinction sociale » (Lipovetsky, 1987, p. 13) ; (3) la mode est un savoir-faire, un art et une industrie créative dont l'enjeu majeur est de produire des symboles, des identités. Comme notre analyse apportera des arguments pour cette troisième dimension, en voici une définition concise : 
La mode est une activité économique parce qu'elle produit des symboles. Elle ne se contente donc pas de transformer du tissu en vêtements, elle crée des objets porteurs de sens. La mode est donc une industrie culturelle ou de la création.

(Godart, 2010, p. 7)

6 La première dimension surgit dans la seconde moitié $\mathrm{du} \mathrm{xx}$ siècle, la troisième ne s'est affirmée que récemment. En revanche, la deuxième, qui est la plus ancienne et remonte aux conceptualisations sociologiques de Georg Simmel et René König, reste dans la littérature académique hongroise d'une importance majeure. Pour Gilles Lipovetsky, elle est largement douteuse et nécessite d'être dépassée :

Un lifting théorique s'impose, il est temps de sortir les analyses de la mode de l'artillerie lourde des classes sociales, de la dialectique de la distinction et de la prétention des classes. À contre-pied de l'impérialisme des schémas de la lutte symbolique des classes, nous avons montré que, dans l'histoire de la mode, ce sont les valeurs et les significations culturelles modernes signifiant en particulier le Nouveau et l'expression de l'individualité humaine qui ont exercé un rôle prépondérant.

(Lipovetsky, 1987, p. 14)

Nous sommes tout à fait d'accord avec l'affirmation de Gilles Lipovetsky selon laquelle cette approche est la seule à donner des résultats pour les cultures où les rapports aux vêtements entrent complètement dans ce paradigme. Mais, à la suite des mouvements migratoires, il n'y a plus de pays occidental qui se caractérise par un seul modèle vestimentaire, la situation étant encore plus compliquée pour les pays, comme la Hongrie, qui n'ont pas complètement adhéré au modèle de l'éphémère et à celui de l'individualisme. Cela se manifeste très clairement dans les réactions des médias hongrois face aux vêtements et aux modes de vie des célébrités hongroises: il s'agit sans cesse de critiquer leur choix sous un angle financier et de ne jamais prêter attention à la signification symbolique ou esthétique de ces "arts de faire ${ }^{3}$ ». Notre argumentation peut paraître contradictoire : nous avons affirmé que le schéma de la distinction sociale n'était plus valable mais avons soutenu qu'il pouvait avoir une certaine importance pour la culture hongroise, et même pour certains aspects du phénomène contemporain de la mode globale. Affirmer que la mode a dépassé le moment où elle était liée à la conscience de classe est une sérieuse colonisation du phénomène mais, en même temps, toute réduction complète du comportement vestimentaire à cette approche ne peut aboutir à des résultats crédibles, même pour une culture où le paradigme de l'individualisme est encore en cours d'affirmation.

8 Mettons brièvement en regard la mode hongroise et la mode française, et soulignons le fait que nous avons affaire à deux cultures radicalement différentes. En ce qui concerne le rapport des Français à la mode, nous pouvons énumérer beaucoup de travaux analysant le prétendu french chic, le rôle de Paris comme capitale de la mode ${ }^{4}$. Il en ressort que pour les Français la mode est depuis longtemps un phénomène culturel majeur. Avec deux semaines de la mode par an, beaucoup d'expositions importantes destinées aux divers aspects du phénomène, plusieurs musées consacrés à la mode et une culture vestimentaire urbaine remarquable, la France reste encore parmi les leaders de la mode globale. En ce qui concerne la Hongrie, cette problématique est beaucoup plus délicate. Malgré l'ambition visible des créateurs contemporains magyars de trouver leur place sur la carte de la mode internationale, il est évident que, dans l'imaginaire social, la mode et la préoccupation vestimentaire restent un domaine négligé, jugé superficiel et sans intérêt. 
9 Pour appuyer ces affirmations, faisons référence à quelques définitions conceptuelles désignant le phénomène de la culture vestimentaire chez les Hongrois, en nous arrêtant sur l'étymologie du mot mode et sur celle de divat. Livrons d'abord l'état des lieux donné par l'article « Mode » de l'Encyclopcedia universalis :

Le français, et diverses autres langues avec lui, désigne par le terme de mode à la fois les canons périodiquement changeants de l'élégance vestimentaire et, plus généralement, les phénomènes d'engouement qui règnent sur le vêtement, mais également sur tout ce qui touche aux "apparences " (la parure, la décoration, les manières, l'intonation, etc.) en tant qu'elles sont dotées d'un pouvoir d'expression. La langue anglaise distingue au contraire fashion, la mode semi-institutionnalisée, socialement approuvée, dont le type est la mode vestimentaire, et fad, l'engouement futile et quelque peu subversif, lui-même distingué de l'engouement en général (craze). Il est remarquable de constater que le terme de mode semble manquer à certains auteurs anglo-saxons, qui parlent de "fad and fashion", tandis qu'au contraire certains auteurs français s'appuient sur la langue anglaise pour distinguer la mode au sens de fashion et la mode au sens de $\mathrm{fad}^{5}$.

10 Il faut aussi souligner que le mot mode dans les langues européennes est intimement lié au mot moderne, et à sa racine se trouve le latin modernus. Or, Ádám Nádasdy affirme que ce dernier adjectif n'existait pas dans le latin ancien, il n'a fait son apparition qu'au $\mathrm{VI}^{\mathrm{e}}$ siècle. À sa base se trouve l'adverbe latin modo dont le sens est en gros « récemment» d'où modernus qui signifie «frais, récent». En allant plus loin, modo provenait du latin modus « mesure » d'où le mot français et allemand mode, et les mots hongrois mód, módi (manière, mode - archaïque ; Nádasdy, 1998, p. 36-38). De notre point de vue, il est extrêmement important que le projet Idixia, né d'une ambition de continuer la méthode derridienne, apporte une nouvelle dimension à cette analyse en affirmant que «la modernité commence quand le mot masculin "un mode" devient féminin, "la mode" ".

11 L'analyse s'efforce de prouver que la mode est la castration du mot mode, et que son rapport à la modernité passe par les processus sociaux de l'émancipation des femmes. Cette perspective féministe fait son apparition chez d'autres théoriciens de la mode, mais nous nous contentons d'attirer l'attention sur cette problématique sans la développer ${ }^{6}$.

En revenant au destin du mot divat, au cours du XIX ${ }^{e}$ siècle, les Hongrois commencent à employer de plus en plus rarement le mot módi pour désigner la mode et le remplacent par divat, lié étymologiquement au substantif 'díj' (valeur, prix) qui a donné plus tard le verbe divik (s'engouer, se passionner). Le premier poème hongrois dédié au phénomène de la mode, le texte de Lőrinc Orczy (« A módi », 1787), emploie encore le mot módi dans son titre. Lőrinc Orczy soutient l'idée que la mode est un comportement imitatif dont le centre se trouve à Paris. Il faut remarquer qu'il y a de nombreux constats dans ce poème qui ont leurs correspondants dans les fameuses critiques religieuses du luxe citées par Daniel Roche (1989, p. 36-39). Une recherche dans les dictionnaires hongrois prouve qu'en sortant du groupe des cultures qui utilisaient un mot lié au moderne et à la modernité pour parler de l'habillement contemporain, les Hongrois ont commencé à ne voir que la nature pécuniaire et dangereuse de la mode. Citons à présent le Magyar Nagylexikon:

Mode: 1. courant temporel dans les goûts, systèmes de coutumes; phénomène sociologique et de psychologie sociale qui dans les sociétés hiérarchiques permet aux groupes sociaux de se rapporter les uns aux autres en s'imitant par des moyens symboliques (habillement, coiffure, manières de comportement, biens de 
consommation, etc.) ; 2. dans un sens plus restreint, changement des formes de l'habillement dirigé par le centre spirituel et économique d'une époque. La mode comprise dans ce sens fait son apparition au moment de la diffusion des habits taillés et de l'apparition des guildes à partir de la seconde moitié du XII ${ }^{\mathrm{e}}$ siècle ${ }^{7}$.

Il est facile de remarquer que toute la dimension identitaire et temporelle du système de la mode manque dans cette définition qui réduit le phénomène à son aspect social et historique. Si les dictionnaires ne sont pas les meilleures sources pour l'analyse des usages des mots, ce passage de módi à divat est symptomatique par rapport à la perte de valeur que la culture vestimentaire subit dans une culture hongroise engoncée dans le schéma de la distinction sociale. Nous allons voir quelle est l'explication historique de cette transformation regrettable. Mais pour regrettable qu'elle soit, la perte de valeur s'accompagne d'une forte émancipation d'une certaine dimension de la culture vestimentaire, celle de l'habillement aristocratique.

\section{Histoires de mode}

Le tournant des $\mathrm{XVIII}^{\mathrm{e}}-\mathrm{XIX}{ }^{\mathrm{e}}$ siècles dans la culture hongroise est la période décisive pour l'arrivée de «la culture des apparences». Inventé par Daniel Roche, ce terme désigne "une manière d'être fugace où l'extravagance, la folie, la valeur marchande et symbolique des choses narguent les façons ordinaires, les plébéiennes et vulgaires habitudes » (Roche, 1989, p. 11).

Dans cette période de transition, le vêtement se trouve au cœur des débats publics sur « la richesse et la pauvreté, l'excès et le nécessaire, le superflu et le suffisant, le luxe et la médiocrité » (Roche, 1989, p. 13).

Au moment où les gens commencent à utiliser le vêtement pour désigner des identités encore très mal définies, l'économie statutaire reste encore très forte sur ses positions et affirme que la consommation doit être liée au statut. Mais en même temps, la rhétorique des civilités fait son apparition et commence à laisser la place à l'opposition de l'être et du paraître dans le système de la société. C'est Gilles Lipovetsky qui conclut sur la nature paradoxale de ce changement : «Paradoxe de la mode : la démonstration affichée des emblèmes de la hiérarchie a participé au mouvement d'égalisation du paraître » (Lipovetsky, 1987, p. 47).

17 Nous insistons sur ce changement parce que, dans la culture hongroise, cette démocratisation des vêtements bourgeois se déroule en parallèle avec le renforcement des codes de l'habit aristocratique. C'est au cours du XIX siècle qu'un mouvement de nationalisation du vêtement aboutit à la naissance des costumes de la cour hongroise qui s'inspirent des habits aristocratiques du $\mathrm{XVI}^{\mathrm{e}}$ siècle tout en gardant - surtout les tenues de femme - des similarités avec les costumes populaires. L'habit de cour des femmes aristocrates hongroises comporte les mêmes éléments que les habits des paysannes, les différences se manifestant moins sur le plan structural qu'en matière de textiles, de broderies et d'ornements. Archaïques et splendides à la fois, ces tenues de cour contrarient et surprennent les autres pays européens habitués à des changements plus rapides en matière de mode et à une simplification et rationalisation des vêtements. Dans un article antérieur (Keszeg 2009), nous avons montré comment la réforme de la langue hongroise (nyelvújitás) s'est accompagnée, chez une de ses figures de proue, d'une ambition unificatrice des costumes nobiliaires du royaume de Hongrie. Nourrissant aussi un grand intérêt pour les arts, Ferenc Kazinczy (1759-1831) essayait 
de se documenter sur les différents types d'habits hongrois; il a jugé nécessaire d'engager un sérieux débat public, avec la participation des intellectuels, sur le choix parmi les éléments de ces tenues. Bien que sa tentative ait été infructueuse, dans les processus d'unification des habits de cour qui ont eu lieu quelques années plus tard, une veste d'homme, le " kazinczy ", porte de nos jours son nom (Keszeg, 2009, p. 15). Ce débat, qui a eu lieu à la fin du XvIII ${ }^{\mathrm{e}}$ siècle, proposait deux attitudes majeures: les conservateurs (ortológusok) soutenaient la nécessité du développement naturel de la langue et critiquaient le groupe des réformateurs (neológusok) qui insistaient sur le renouveau du lexique et sur l'invention de nouveaux mots. Pour Ferenc Kazinczy, les étapes de cette dispute se déroulaient en parallèle avec le débat sur la nécessité d'unifier l'habit national. Tantôt il optait pour un costume national créé à partir des éléments des habits nobiliaires, tantôt il prônait l'existence des pièces vestimentaires hongroises dignes de cet habit. Dans les dernières années du xvIII siècle, Ferenc Kazinczy prêtait une attention particulière à l'emploi des habits nobiliaires hongrois dans ses propres choix vestimentaires, et ce après avoir suivi de près les changements des modes européennes par le biais de la cour de Vienne.

Le sociologue Péter Zsolt remarque le paradoxe de ce phénomène : les nobles hongrois, poussés par un désir éducatif, étaient en même temps tragiquement rejetés par les couches plus modestes.

À vrai dire, les élites de notre société essayaient de créer une mode et de diffuser leur attitude prosociale. C'est dans cette ambition que les élites des sociétés se trouvant à l'est de l'Elbe se distinguent de celles à l'ouest; l'éducation prosociale des Occidentaux ne s'accompagne pas d'un désir d'éducation de la nation, d'un sens d'exemplarité affirmée et d'un comportement ostentatoire, mais d'un intérêt personnel utilitariste et d'une volonté manipulatrice dans le bon sens du terme. Le pathos manquait ou avait disparu plus tôt de leur style de vie.

(Zsolt, 2007, p. 52-53)

L'affirmation de Péter Zsolt s'applique bien à Ferenc Kazinczy dont les choix vestimentaires, malgré son ambition de s'intégrer dans plusieurs groupes sociaux, étaient souvent considérés comme snobs et inadaptés ${ }^{8}$.

L'argumentation fondée sur le manque de spontanéité paraît un peu simpliste, mais le diagnostic concernant les différences dans le pouvoir d'influencer des élites de l'Ouest et de l'Est semble juste. Au niveau de l'évolution de la mode, ce constat se manifeste dans le développement, au $\mathrm{xx}^{\mathrm{e}}$ siècle, d'une mode d'inspiration nationale (tant des habits de cour que des costumes populaires) récurrente à l'époque du communisme et même après la chute du régime, de manière plus ou moins ironique. Malgré quelques maisons de couture ayant une identité bourgeoise, comme le salon de Klára Rotschild (1953-1976), l'inspiration populaire et les vêtements de cour restent la tradition la plus autochtone de l'habillement hongrois. Il faut retenir que toute cette tradition se maintient encore hors de la culture des apparences, hors de l'histoire de la mode et reste coincée dans l'histoire du costume. Il a fallu attendre la chute du communisme pour voir débuter une vraie et nouvelle histoire de la mode en Hongrie.

\section{Histoires de professionnels de la mode}

21 Nous arrivons au troisième moment de notre étude, celui des différences entre les histoires de vie des professionnels et leurs possibilités de faire carrière dans deux industries complètement différentes. Nous allons nous arrêter sur deux cas typiques de 
carrière : celui de Klára Zsindelyné Tüdős (1895-1980), contemporaine d'Elsa Schiaparelli, et celui de Tamás Király (1952-2013), créateur contemporain de la génération de Jean-Paul Gaultier.

Klára Tüdős ouvre son salon en 1936 à Budapest et doit le fermer au début de la Seconde Guerre mondiale. Si l'occupation allemande fut un choc pour la couture française, les Allemands manifestaient néanmoins un très grand intérêt pour la mode. Du coup, l'enjeu pour les maisons françaises de couture variait entre sécurité et intégrité face à une forte volonté d'assimilation :

À l'image de la société française, toutes les attitudes ont donc coexisté dans la haute couture. Certains couturiers oscillent entre le refus pur et simple comme Elsa Schiaparelli. Madame Grès résiste à sa façon sans tenir compte des directives allemandes concernant les métrages imposés. Jacques Heim poursuit ses activités tout en se cachant. Jeanne Lanvin tolère la présence d'Allemands lors de ses collections mais ne va pas au-devant. Lucien Lelong pour sauvegarder la couture et préserver la main-d'œuvre s'est engagé sur la voie d'une collaboration minimale mais n'en a tiré aucun profit personnel. D'autres maisons (Fath, Rochas, Maggy Rouff) ont misé sur une victoire allemande, et se sont enrichies, profitant de toutes les occasions. Entre les deux, ceux que l'on peut qualifier de modérés ont attendu des jours meilleurs se contentant de subir un minimum de coopération.

(Veillon, 2014, p. 201)

Quant à Klára Tüdős, elle n'a pas la possibilité de pouvoir garder son salon. Malgré le statut de son mari, ministre du Commerce de 1943 à 1944, le couple déploie une activité antinazie et cache dans sa villa 72 réfugiés, des enfants comme des Juifs. Pendant la période du communisme, ils sont condamnés à cause de leur passé politique et trouvent refuge dans la modeste maison de service de leur villa, à Balatonlelle. Faute de pouvoir créer un nouveau salon, Klára Tüdős devient une des fondatrices du mouvement des femmes protestantes. Tout au long de sa carrière exemplaire et inhabituelle, Klára Tüdős surprend par sa capacité de toujours recommencer et trouver de nouveaux défis dans les situations difficiles.

Le début de sa carrière de couturière prend sa source dans le monde du théâtre, son intérêt pour la mode étant lié à sa profession de costumière de théâtre. Le fait que Klára Tüdős, dont les collections jouissaient de très bons commentaires dans la presse contemporaine, avait un certain succès grâce aux critiques de théâtre qui - connaissant son œuvre théâtrale - lui restaient fidèles, témoigne de la très pauvre autonomisation du champ de la mode hongroise des années 1930. Ainsi, la plus importante carrière de la mode de l'entre-deux-guerres est une carrière théâtrale bifurquant vers la mode bourgeoise. Au milieu du nationalisme des années 1930, la couturière a découvert que les motifs des costumes populaires et des costumes nobiliaires pouvaient s'adapter facilement aux tendances européennes. Bénéficiant d'une bonne connaissance des régions de la Hongrie et ayant également fait des études d'ethnographie, Klára Tüdős a bâti une importante collection de vêtements populaires en s'inspirant des tenues originales qu'elle étudiait très méticuleusement. Cet intérêt pour la culture matérielle paysanne trouve son origine dans une éducation à l'étranger qui lui avait donné la possibilité de porter un regard extérieur sur la culture de son pays. La villa où elle a développé son activité antinazie était meublée de mobilier paysan, de tissus qui provenaient de tous les coins de la Hongrie. La carrière de Klára Tüdős prouve de façon éclatante que l'effervescence des années 1930 s'est arrêtée non seulement à cause de la guerre, mais davantage encore en raison de l'installation du régime communiste qui ne laissait qu'une place très restreinte au développement de la mode. Dans une 
perspective historique, ce cas est très significatif parce qu'il montre que les principaux succès internationaux de la couture hongroise reposaient sur l'héritage de la mode aristocratique et populaire, et non pas sur une activité créative autonome et soutenue.

Notre second exemple porte sur le récit de vie d'un créateur isolé et au destin tragique : Tamás Király, figure très importante du mouvement underground hongrois de l'époque du communisme. Ses créations, s'inspirant des vêtements de la rue et marquées par l'esprit de la déconstruction, étaient portées par les représentants des cercles d'artistes underground des années 1970-1980. Avec un sens du spectacle et une ironie tournée souvent contre les institutions conservatrices de la Hongrie, Tamás Király aimait choquer et déstabiliser. En lisant les témoignages recueillis par un de ses anciens mannequins (Fazekas, 2014), nous sommes interpellées aussi bien par l'absence d'une industrie professionnelle hongroise que par la nature arbitraire des relations entre créateurs, clients, photographes, journalistes et couturières. Toute la beauté des milieux de l'underground s'y dévoile: une absence complète de soucis financiers; de grandes amitiés et de grands conflits érigés en principe de fonctionnement d'un cercle de personnes ayant le même intérêt; une volonté de choquer et de se heurter à un régime dont on ignore volontairement la nature imposée; une place centrale et incontournable accordée à la créativité et une dénégation de toute autre ressource nécessaire pour un travail de création. Le plus important moment de la carrière de Tamás Király a eu lieu en 1988 quand il a été invité à Berlin pour présenter sa collection dans le programme Dressater, aux côtés de figures iconiques de la mode ${ }^{9}$. Dans ce groupe de créateurs avant-gardistes, Tamás Király est le plus oriental et le seul dont la carrière s'arrête brusquement après la chute du communisme. Dans le volume mentionné plus haut, de nombreux amis et collaborateurs de Tamás Király expriment leur hébétude devant le retard de son succès après la chute du régime. Plusieurs étaient convaincus qu'avec le changement de régime, la carrière de Tamás Király allait s'envoler et que la reconnaissance internationale ne tarderait pas à arriver. Mais il en fut autrement: en avril 2013, Tamás Király a été assassiné par un partenaire sexuel occasionnel. Sans revenus considérables, sans marque propre, sans reconnaissance internationale, il faisait figure de créateur bizarre, respecté mais ignoré, l'ombre de celui qui avait représenté quelques décennies plus tôt l'art underground de Budapest.

Quelles sont les raisons de cette chute? D'un côté, il faut attirer l'attention sur l'importance croissante du marketing dans l'univers européen de la mode dès les années 1980, changement auquel de nombreux créateurs avant-gardistes européens n'ont pas réussi à faire face. D'un autre côté, le grand désavantage de Tamás Király résidait dans son indifférence envers l'industrialisation de la création, d'où son incapacité à s'intégrer dans un marché de plus en plus demandeur et laissant de moins en moins de place à la créativité spontanée. Pour Tamás Király, la chute du régime a été à la fois tardive et prématurée : il n'a pas eu la possibilité d'apprendre les manières de s'affirmer dans le milieu de la mode européenne et, en même temps, il a dû assister à son propre échec. 


\section{BIBLIOGRAPHIE}

CSIPES Antal, 2011, A divatról komolyan (Sur la mode sérieusement), Budapest: Balassi.

CERTEAU Michel DE, 1990, l'Invention du quotidien 1. Arts de faire, Paris : Gallimard, « Folio, Essais », 146.

DIZSERI Eszter, 1994, Zsindelyné Tüdős Klára (Klára Tüdős, ép. Zsindely), Budapest: Kálvin.

F. DózSA Katalin, 2014, Megbámulni és megbámultatni. Viselettörténeti tanulmányok (Contempler et faire contempler. Études sur l'histoire de l'habillement), Budapest: L'Harmattan.

FAZEKAS Orsolya, 2014, Csak vállfákat hozzatok! - Király Tamás, a divatmüvész (N’apportez que des cintres. Tamás Király, l’artiste de la mode), Budapest: Alinea.

GODART Frédéric, 2010, Sociologie de la mode, Paris : La Découverte, « Repères », 544.

KAZINCZY Ferenc, 1890-1911, Levelezése I-XXI (Correspondance), édité par János Váczy, Budapest.

KAZINCZY Ferenc, 2009, Pályám emlékezete (Souvenir de mon parcours), édité par László Orbán, Debrecen University Press.

KESZEG Anna, 2009, „A szabó Kazinczy. Módi és viselet összefüggései Kazinczy Ferencnél” (Kazinczy le couturier. Corrélations entre mode et vêtement chez Ferenc Kazinczy), in CZIFRA Mariann (ed.), Leleplezett mellszobor. Nyomozások Kazinczy Ferenc birtokán (Un buste découvert. Enquêtes sur les terres de Ferenc Kazinczy), Budapest: Gondolat, p. 9-42.

KESZEG Anna, 2015, „Király Tamás, a kifutó tervező: Az avantgárd tervező és az ökodivat jelenségének konfliktusa" (Tamás Király, le créateur hors mode : le conflit entre le phénomène de la mode écologique et un créateur d'avant-garde), in UNGVÁRI ZRÍNYI Imre (ed.), Az élet gondnokai és az ember szabadsága: Élettisztelet, életértékek, életpolitikák (Les gardiens de la vie et la liberté de l'homme : respect de la vie, valeur de la vie, politiques de vie), Cluj-Napoca: Egyetemi Műhely, p. 93-105.

LIPOVETSKY Gilles, 1987, l'Empire de l'éphémère, la mode et son destin dans les sociétés modernes, Paris : Gallimard, « Folio, Essais », 170.

NÁDASDY Ádám, 1998, „A ‘modern' és a belőle képzett fogalmak jelentés-és használattörténete” (Le « moderne » et l'histoire de la sémantique et de l'usage des concepts dérivés), Replika, 30, pp. 33-40.

ORCZY Lőrinc, 1787, Költeményes holmi egy nagyságos elmétől (Affaires poétiques dans l'esprit d'un seigneur), Pozsony: Loewe Antal.

ROCHE Daniel, 1989, la Culture des apparences. Une histoire du vêtement XVII ${ }^{e}$-XVIII ${ }^{e}$ siècle, Paris : Fayard, « Points », H139.

SKODA Claudia \& SCHNEIDER Susanne, 1988, Dressater. Ein neues Medium, Berlin:

Tempo-Claudia Skoda.

STEELE Valerie, 1998, Paris Fashion. A Cultural History, Oxford: Berg Publishers.

VEILLON Dominique, 2014, la Mode sous l'Occupation, Paris : Payot/Rivages, « Petite Bibliothèque Payot », 988. 
VINKEN Barbara, 2004, Fashion Zeitgeist. Trends and Cycles in the Fashion System, Oxford: Berg Publishers.

zsolt Péter, 2007, Divatszociológia (Sociologie de la mode), Budapest: Pro Die.

\section{NOTES}

1. Cet ouvrage, publié en 2010 , comporte dix volumes.

2. En hongrois : Az ezredforduló után a divat első számú kulturális tényezővé vált. A társadalom a tömegfogyasztásnak és a tömegkommunikációnak köszönhetően átrendezödött: a divat nemcsak az öltözködéshez kapcsolódott, hanem egyre több területre volt hatással. A design, a reklám, a sportok, az egészség, a szokások, a megjelenés a társadalom egészét befolyásolta és újrastrukturálta (traduction de l'auteure).

3. Nous utilisons le concept tiré de la célèbre définition donnée par Michel de Certeau dont le livre a eu un grand écho dans les sciences des médias : "Par ce biais "la culture populaire" se présente différemment, ainsi que toute une littérature dite "populaire": elle se formule essentiellement en "arts de faire" ceci et cela, c'est-à-dire en consommations combinatoires et utilisatrices. Ces pratiques mettent en jeu un ratio "populaire", une manière de penser investie dans une manière d'agir, un art de combiner indissociable d'un art d'utiliser » (De Certeau, 1990, p. XLI).

4. Voir STEELE, 1998. Le livre présente un survol bibliographique très convaincant, p. 3-13.

5. BESNARD Philippe \& BURGELIN Olivier, "Mode, sociologie ", Encyclopcedia universalis (en ligne), http://www.universalis.fr/encyclopedie/mode-sociologie/ [consulté le 8 mai 2016].

6. «L'étymologie du mot moderne est transsexuelle. À partir du mode, modi, concept sérieux s'il en est (inventé par Aristote), tout d'un coup, on ne sait pourquoi, des mauvais plaisants ont procédé à une opération inattendue et d'un goût douteux, ils ont inventé la mode, cette transsexuelle. La mode n'est pas sérieuse, elle est vicissitude, elle est illusion, elle est l'inconstance du temps qui passe. Elle est encore pire qu'un accident: elle est un caprice imprévisible et tyrannique ", VALKAMA Jim, 2007, le Moderne et son autre, Paris : Galgal, reprise sur Idixia, page créée le 31 juillet 2000 (en ligne), http://www.idixa.net/Pixa/ pagixa-0501201303.html [consulté le 8 mai 2016].

7. BERÉNYI Gábor, 1998, „Divat”, in BERÉNYI Gábor (ed.), Magyar Nagylexikon. VI. Budapest: Magyar Nagylexikon, pp. 662-663. „Divat: 1. átmenetileg uralkodó ízlésirány, szokásrendszer; olyan szociológiai és tömeglélektani jelenség, amely a hierarchikusan tagolt társadalmakban a csoportok tagjai számára lehetővé teszi, hogy az utánzás révén szimbolikus eszközök (ruházat, hajviselet, modor, fogasztási cikkek stb.) segitségével egymáshoz viszonyitsák magukat. 2. szükebb értelemben az öltözködési formák változása, amit egy-egy korszak szellemi és gazdasági központja irányít. A szónak ebben az értelmében vett divat a szabott ruha elterjedésével, a céhek kialakulásával párhuzamosan a 12. sz. második felétöl követhető nyomon" (traduction de l'auteure).

8. Les constats de cette partie s'appuient sur les écrits autobiographiques et les lettres de Ferenc Kazinczy, cités en bibliographie.

9. La liste est longue: l'Irlandais Tom Adams, l'Espagnol Francis Montesinos, l'Anglaise Vivienne Westwood, le Japonais Yoshiki Hishinuma, le Français Marc Audibet, l'Autrichien Rudi Gernreich et l'Allemande Claudia Skoda. C'est à la suite de cet événement que la presse allemande avait qualifié Király de « Jean-Paul Gaultier de l'Europe de l'Est ». 


\section{RÉSUMÉS}

Le présent article saisit les problèmes auxquels un projet d'histoire sociale de la mode hongroise se heurte. L'analyse propose une démarche à trois niveaux : premièrement, elle présente une recherche discursive relative à la place que les mots et les expressions liées à la mode occupent dans la culture hongroise; deuxièmement, elle s'intéresse à l'histoire du phénomène vestimentaire et à l'apparition plus ou moins tardive de la mode dans l'histoire de l'habillement ; enfin, elle présente de courtes études de cas des faits et des processus de l'industrie de la mode et de sa professionnalisation en Hongrie.

The main goal of the article is to summarize the problems of a social history of Hungarian fashion. As a result it presents three aspects of the question. On the one hand an overview of fashion related words and expressions points out the place that fashion holds in Hungarian cultural imaginary. On the other hand a historical inquiry traces the process by which fashion makes his apparition in the longer history of costume and dress. Finally a couple of case studies demonstrate how difficult was and still is the professionalization of the designer and the birth of fashion industry in Hungary.

Jelen írás a magyar divat egy lehetséges társadalomtörténeti összefoglalójának problémáit tekinti át. Megközelítése háromszintű: mindenekelőtt a beszédmódok és fogalomhasználatok kérdéskörét elemzi azt vizsgálva, hogy a divattal kapcsolatos szavak és kifejezések milyen helyet foglalnak el a magyar kultúrában; másodsorban történeti összefüggésben arra kérdez rá, hogy a divat sajátos jelensége mikor, milyen feltételek mellett, mekkora megkésettséggel jelenik meg az öltözködéskultúra hosszabb időtartamú történetében; végül pedig néhány esettanulnányom keresztül a magyar divatipar és a divat professzionalizációjának folyamatára és csomópontjaira kérdez rá.

\section{INDEX}

Index géographique : Angleterre, Belgique, Budapest, France, Hongrie, États-Unis, Vienne motscleset mood motsclesru МОДА

Keywords : fashion

Mots-clés : mode, mode

nomsmotscles Allemands, Français, Hongrois

Thèmes : sociologie

Index chronologique : XXe siècle

disciplines anglais, français, hongrois 